\title{
Polarization Lidar Detection of Agricultural Aerosol Emissions
}

\author{
Eduard Gregorio $\mathbb{D}^{1},{ }^{1}$ Jordi Gené, ${ }^{1}$ Ricardo Sanz, ${ }^{1}$ Francesc Rocadenbosch, ${ }^{2}$ Patricia Chueca, ${ }^{3}$ \\ Jaume Arnó, ${ }^{1}$ Francesc Solanelles, ${ }^{4}$ and Joan R. Rosell-Polo ${ }^{1}$ \\ ${ }^{1}$ Research Group in AgroICT \& Precision Agriculture, Department of Agricultural and Forest Engineering, Universitat de Lleida \\ (UdL)-Agrotecnio Center, Lleida, Spain \\ ${ }^{2}$ Remote Sensing Laboratory, Department of Signal Theory and Communications, Universitat Politècnica de Catalunya (UPC)/IEEC, \\ Barcelona, Spain \\ ${ }^{3}$ Centro de Agroingeniería, Instituto Valenciano de Investigaciones Agrarias (IVIA), Moncada, Valencia, Spain \\ ${ }^{4}$ Department of Agriculture, Livestock, Fisheries and Food, Generalitat de Catalunya, Lleida, Spain \\ Correspondence should be addressed to Eduard Gregorio; egregorio@eagrof.udl.cat
}

Received 15 October 2017; Revised 26 January 2018; Accepted 8 February 2018; Published 18 April 2018

Academic Editor: Yasuko Y. Maruo

Copyright (C) 2018 Eduard Gregorio et al. This is an open access article distributed under the Creative Commons Attribution License, which permits unrestricted use, distribution, and reproduction in any medium, provided the original work is properly cited.

\begin{abstract}
Agricultural aerosol emissions can significantly impact human and animal health as well as the environment. Therefore, it is essential to adopt new sensing techniques for real-time monitoring these emissions in high temporal and spatial resolution. In recent years, light detection and ranging (lidar) technology has been used for measuring the particulate matter emitted from agricultural operations. However, conventional nonpolarized lidar systems cannot discriminate between different types of aerosols, which can lead to misinterpretation of the results. To overcome this limitation, this study applies the polarization lidar technique to monitor agricultural aerosols. A $355 \mathrm{~nm}$ polarization lidar system was used to measure the emissions generated during pesticide spraying operations. The results showed that depolarization ratios due to field dust $(0.220-0.268)$ and to road dust (0.385) are clearly higher than those caused by pesticide spray drift (0.028-0.043) or by diesel exhaust (0.099), which can be used to differentiate each type of aerosol. These results support the development of new polarization lidar systems specifically designed to study the impact of agricultural activities on air quality.
\end{abstract}

\section{Introduction}

Agricultural and livestock farming generates considerable aerosol emissions, including particulate matter (PM) and pesticides. Agricultural activities are responsible for $5 \%$ of all particles less than $2.5 \mu \mathrm{m}$ in diameter $\left(\mathrm{PM}_{2.5}\right)$ and $25 \%$ of all particles less than $10 \mu \mathrm{m}\left(\mathrm{PM}_{10}\right)$ [1]. The main agricultural activities responsible for PM emissions are tilling, harvesting, agricultural fires, and emissions from fertilizer use and livestock [2]. Pesticide spray drift is another large source of pollution. Spray drift losses can be as great as $30-50 \%$ of the applied product [3]. These aerosols have a negative effect on the environment and air quality, entailing serious risks to human and animal health. For example, PM has been linked to cardiac and respiratory diseases [4]. In addition, spray drift can damage crops close to the treated area, contaminate surface water, and reach residential areas. It has been demonstrated that pesticides can travel thousands of kilometers and have been found in areas as remote as the polar regions [5].

Monitoring these aerosols is extremely important due to the need to identify their sources, evaluate their effects, and propose appropriate mitigation measures. Point samplers are commonly used but unable to provide a full view of the emitted plume, and they are labor-intensive and time-consuming. Light detection and ranging (lidar) is an optical remote sensing technique that can overcome these limitations. Lidar systems can provide real-time aerosol measurements with high temporal and spatial resolution. In previous studies, nonpolarized lidar systems have been used to measure $\mathrm{PM}_{10}$ emissions from land preparation operations [6-9] to determine vertical PM concentration 


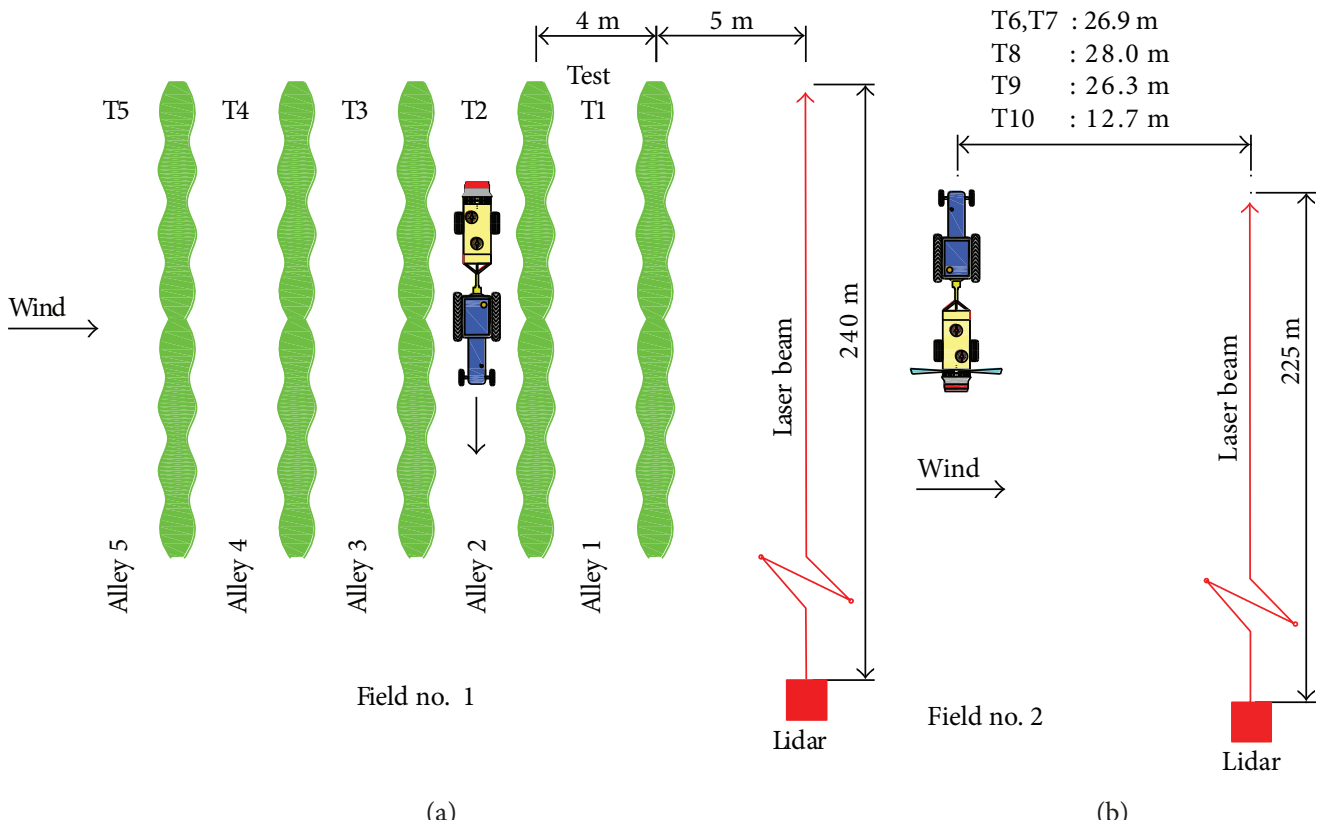

(a)

(b)

Figure 1: Experimental setup with sprayer and lidar location: (a) field no. 1: trials T1 to T5; (b) field no. 2: trials T6 to T10.

profiles. Several lidar studies have also been carried out to estimate the PM emissions due to livestock housing. For example, PM concentration and fluxes generated by a swine-feeding facility have been measured using a threewavelength lidar system in combination with mass samplers and optical particle counters [10]. An alternative methodology has been recently developed to estimate the PM emission rates from animal production facilities departing from single-wavelength lidar data [11]. In another study [12], a scanning lidar system was used to obtain the backscatter coefficients of aerosols emitted by a pig farm. Lidar technology has also been applied in spray drift studies to assess the dynamics of aerially released pesticides [13-15], to study the influence of atmospheric stability over spray dispersal $[16,17]$, and to quantify the spray plume concentration [18]. High correlations between lidar and collector measurements of spray drift have been obtained in recent studies [19-21]. Lidar systems are also a suitable tool to validate spray-transport models [22] and dust plume dispersal models of agriculture field operations [23, 24].

The development of new eye-safe scanning lidar systems specifically designed for agricultural applications $[25,26]$ is expected to contribute to agricultural air quality monitoring. Nevertheless, conventional lidar systems are unable to distinguish between different types of aerosols, which can lead to misinterpretation of the measurements. For example, in a terrestrial spray drift study, the return signal captured by a nonpolarized lidar system may be assumed to be due solely to the drift plume generated by the sprayer. However, the return signal could be contaminated by dust or other unexpected aerosols. Unlike conventional systems, polarization lidars can differentiate aerosols by their shape [27]. Polarization lidar systems are used to identify the presence of ice crystals in mixed-phase clouds [28], for the detection of desert dust in the troposphere [29], to study the polar stratospheric clouds [30], and to measure the contrails produced by aircraft [31], among other applications. In this work, a polarization lidar system is used to measure air emissions generated during spraying operations with an air-assisted sprayer. Although polarization lidar systems are a wellestablished tool for atmospheric research, to the authors' knowledge, they have not been previously applied for the monitoring and identification of agricultural emissions. The aim of this work is to determine if the polarization lidar technique is a suitable method for unambiguously discriminating between different types of agricultural aerosol emissions.

\section{Materials and Methods}

2.1. Experimental Setup. The trials were conducted in two fields owned by the Institut de Recerca i Tecnologia Agroalimentàries in Gimenells (lat. $41^{\circ} 39^{\prime} 11^{\prime \prime} \mathrm{N}$, long. $0^{\circ} 23^{\prime} 28^{\prime \prime} \mathrm{E}$, elev. $259 \mathrm{~m}$ ) located about $25 \mathrm{~km}$ from Lleida, Spain. Figure 1 shows the experimental setup at both study sites. Field no. 1 was an apple orchard, while field no. 2 was a flat fallow field. An air-assisted sprayer (Ilemo Arrow F-1000, Ilemo/Hardi SA, Lleida, Spain) and three nozzle types, a hollow cone (Albuz ATR Orange, Saint-Gobain, Evreux, France), an air injected low drift (Albuz TVI 8002 Yellow), and a disc-core full cone (Teejet D3DC35, Spraying Systems Co., Wheaton, Illinois, USA), were used. Aerosol measurements were carried out using a polarization lidar system (ALS 300, Leosphere, Orsay, France). This system transmits $16 \mathrm{~mJ}$ laser pulses at $355 \mathrm{~nm}$ (tripled Nd:YAG) with a pulse repetition frequency of $20 \mathrm{~Hz}$ [32]. The temporal and spatial resolutions were adjusted to $1 \mathrm{~s}$ and $1.5 \mathrm{~m}$, respectively. The range of full overlap, i.e., the distance from which the full laser beam is seen within the receiver field of view, was adjusted to $80 \mathrm{~m}$. In all the trials, the lidar system was located farther than $200 \mathrm{~m}$ from the sprayer (Figure 1). This distance 
TABLE 1: Experimental field trials.

\begin{tabular}{lcccccccc}
\hline Trial & Location & Vegetation (alley) & Operational mode & Sprayer fan & Spraying & Model & Nozzles & Number \\
Flow rate \\
(l min $^{-1}{\text { nozzle })^{1}}^{1}$
\end{tabular}

${ }^{1}$ Individual nozzle flow rate at a pressure of $1 \mathrm{MPa}$.

ensured that the aerosol was always measured within the full overlap area.

The goal of the trials conducted in field no. 1 (trials T1 to T5) was to measure the different types of aerosols emitted during terrestrial spraying operations. In trial T1, the sprayer was kept in a static position and located in alley 1 (Figure 1(a)). In this trial, the tractor motor was turned on for $30 \mathrm{~s}$ without spraying and with the fan off, thus only diesel exhaust was emitted. Trial T2 was carried out in alley 2 , and in this case, the sprayer travelled a total distance of $50 \mathrm{~m}$ along the alley within $30 \mathrm{~s}$ (dynamic trial). This trial was carried out without spraying but with the fan on, raising field dust. Trial T3 was similar to T2, but it was conducted in alley 3. T4 and T5 were dynamic trials in which spraying was carried out. Trial $\mathrm{T} 4$ was performed in alley 4 , while trial $\mathrm{T} 5$ was conducted in alley 5 .

In trials $\mathrm{T} 1$ to $\mathrm{T} 4$, the speed of the power take-off (PTO) was $370 \mathrm{rpm}$, while in trial T5 it was increased to $540 \mathrm{rpm}$. The lidar system was kept in a static position during all trials. The laser beam was pointed horizontally and aligned parallel to the first row of trees in the apple orchard. The separation between this row and the laser beam was $5 \mathrm{~m}$. The purpose of this setup was to measure the emitted aerosol that was able to travel past the treated crop and reach the neighbouring field. Five spray trials (T6 to T10) with a duration of $30 \mathrm{~s}$ were carried out in field no 2. As shown in Figure 1(b), the sprayer position was adjusted in each trial to ensure that the spray drift always reached the measurement area.

Table 1 shows the experimental conditions of all the trials. For each trial, the following information is provided: experimental field, presence or absence of vegetation, alley where the sprayer was placed, operational mode of the sprayer, sprayer fan setting, spraying application, nozzle model employed, number of open nozzles, and individual flow rate.

2.2. Polarization Lidar Methodology. Polarization lidar systems are based on the emission of linearly polarized light and the detection of the return power in the orthogonal and parallel planes of polarization. Range-corrected parallel and orthogonal backscatter lidar signals are given by

$$
\begin{gathered}
U_{\|}(R)=K_{\|} \beta_{\|}(R) T^{2}(R), \\
U_{\perp}(R)=K_{\perp} \beta_{\perp}(R) T^{2}(R),
\end{gathered}
$$

where $U_{\|}$and $U_{\perp}$ are the range-corrected return powers in the parallel and orthogonal planes of polarization, respectively. $K_{\|}$and $K_{\perp}$ are the system constants for the two channels. $\beta_{\|}$and $\beta_{\perp}$ are the total parallel- and the total orthogonal-polarized backscatter coefficients, and $T^{2}(R)$ is the two-way atmospheric transmittance.

The linear volume depolarization ratio $\delta_{\mathrm{v}}$ is used to quantify the degree of depolarization of the backscattered light and is defined by

$$
\delta_{\mathrm{v}}(R)=\frac{\beta_{\perp}(R)}{\beta_{\|}(R)} .
$$

Substituting (1) into (2), the following expressions [33] are obtained for the linear volume depolarization ratio $\delta_{\mathrm{v}}$ and for the range-corrected total backscatter signal $U$ :

$$
\begin{aligned}
\delta_{\mathrm{v}}(R) & =\frac{U_{\perp}(R)}{K^{*} U_{\|}(R)}, \\
U(R) & =U_{\|}(R)+\frac{U_{\perp}(R)}{K^{*}},
\end{aligned}
$$

where $K^{*}=K_{\perp} / K_{\|}$is the cross-calibration constant. Following [34], the value of $K^{*}$ depends on the optics transmissivity of the Brewster plates used to separate both polarizations and is given by

$$
K^{*}=\frac{U_{\perp}(R) T_{\|}^{1}}{U_{\|}(R)\left[\left(1-T_{\|}^{1}\right)\left(1-T_{\|}^{2}\right)+\delta_{v}(R)\right]},
$$

where $T_{\|}^{1}$ and $T_{\|}^{2}$ are the transmissions of the parallel polarization contributions of the two Brewster plates, estimated as $T_{\|}^{1}=T_{\|}^{2}=0.92$ (Dr. P. Chazette, private communication). 
Using vertical profile measurements with our ALS300 system and calibration of the volume depolarization in a molecular reference layer (height interval: 4000-4500 m), a cross-calibration constant $K^{*}=20.9 \pm 0.7$ was obtained. In detail, this methodology assumes $\delta_{\mathrm{v}}=\delta_{\mathrm{m}}$, where $\delta_{\mathrm{m}}$ is the molecular depolarization ratio. At a wavelength of $355 \mathrm{~nm}$, a value of $\delta_{\mathrm{m}}=0.00395$ has been considered [35]. The obtained cross-calibration constant figure is similar to the one estimated by Chazette et al. [34] for the homemade version of the ALS system.

With $K^{*}$ known, the polarization system becomes calibrated and the volume depolarization ratio $\delta_{\mathrm{V}}$ can be readily retrieved from (3) and the measurements of $U_{\|}$ and $U_{\perp}$.

The volume depolarization ratio depends on the type and concentration of the aerosols present in the atmosphere as well as on the molecular contribution. Therefore, to identify different types of aerosols, it is necessary to determine the linear particle depolarization ratio $\delta_{\mathrm{p}}$ as it only depends on particle properties. For example, large values of $\delta_{p}$ correspond to nonspherical particles or to particles with a nonhomogenous diffraction index.

In vertical lidar sounding of the atmosphere, the particle depolarization ratio $\delta_{\mathrm{p}}$ is related to the volume depolarization ratio $\delta_{\mathrm{v}}$ as $[36]$

$$
\delta_{\mathrm{p}}=\frac{\left(1+\delta_{\mathrm{m}}\right) \delta_{\mathrm{v}} R_{\mathrm{p}}-\left(1+\delta_{\mathrm{v}}\right) \delta_{\mathrm{m}}}{\left(1+\delta_{\mathrm{m}}\right) R_{\mathrm{p}}-\left(1+\delta_{\mathrm{v}}\right)},
$$

where $R_{\mathrm{p}}$ is the backscatter ratio, given by

$$
R_{\mathrm{p}}=\frac{\beta_{\mathrm{m}}+\beta_{\mathrm{p}}}{\beta_{\mathrm{m}}},
$$

where $\beta_{\mathrm{m}}$ and $\beta_{\mathrm{p}}$ are the molecular and particle backscatter coefficients, respectively.

Whereas in ground-based vertical lidar sounding, subscripts " $p$ " and " $m$ " refer to the particle and molecular components, respectively, in the horizontal lidar sounding addressed in this work, subscripts " $b$ " and " $p$ " refer to the background component and to the agricultural aerosol component. The background component comprises both aerosols and molecules along the horizontal path when the tractor and the sprayer are off. Equations (6) and (7) are rewritten and adapted according to such analogy of variables:

$$
\begin{aligned}
& \delta_{\mathrm{p}}=\frac{\left(1+\delta_{\mathrm{b}}\right) \delta_{\mathrm{v}} R_{\mathrm{p}}-\left(1+\delta_{\mathrm{v}}\right) \delta_{\mathrm{b}}}{\left(1+\delta_{\mathrm{b}}\right) R_{\mathrm{p}}-\left(1+\delta_{\mathrm{v}}\right)}, \\
& R_{\mathrm{p}}=\frac{\beta_{\mathrm{b}}+\beta_{\mathrm{p}}}{\beta_{\mathrm{b}}},
\end{aligned}
$$

where $\delta_{\mathrm{b}}$ is the volume background depolarization ratio and $\beta_{\mathrm{b}}$ is the background backscatter coefficient. $\delta_{\mathrm{b}}$ is obtained by computing the volume depolarization ratio (3) given tractoroff measured range-corrected orthogonal and parallel power profiles, $U_{\perp}$ and $U_{\|}$, respectively, along the horizontal path, and calibration constant $K^{*}$. The volume depolarization ratio $\delta_{\mathrm{v}}$ is measured with the tractor on. The backscatter ratio $R_{\mathrm{p}}$ is computed as the ratio of the total (background + agricultural aerosol), $U_{\text {tot }}$, to the background range-corrected power, $U_{\mathrm{b}}$,

$$
R_{\mathrm{p}}(R) \approx \frac{U_{\mathrm{tot}}(R)}{U_{\mathrm{b}}(R)}, \quad R \in[a, b],
$$

where

$$
\begin{aligned}
U_{\text {tot }}(R) & =\left[\beta_{\mathrm{b}}+\beta_{\mathrm{p}}(R)\right] T_{\mathrm{b}}^{2}(R) T_{\mathrm{p}}^{2}(R), \\
U_{\mathrm{b}}(R) & =\beta_{\mathrm{b}} T_{\mathrm{b}}^{2}(R), \quad R \in[a, b],
\end{aligned}
$$

where $R$ is the range along the horizontal path and $a$ and $b$ are the initial and final ranges of the aerosol cloud, $0<a<$ $R<b<R_{\max }$, with $R_{\max }$ being the maximum range. $T_{\mathrm{b}}^{2}(R)$ and $T_{\mathrm{p}}^{2}(R)$ are the optical transmittances due to background and particle (agricultural aerosol) extinctions, respectively. Equation (10) approximation essentially assumes that the two-way particle transmission is close to unity, $T_{\mathrm{p}}^{2}(R) \approx 1$, or, equivalently, that the optical depth in $[a, b]$ is much smaller than unity, $\tau_{\mathrm{P}}=\int_{a}^{b} \alpha_{\mathrm{P}}(u) d u \ll 1$, where $\alpha_{\mathrm{p}}$ is the particle extinction coefficient.

2.3. Lidar Data Analysis. The received lidar data was background-subtracted to remove the residual skylight and offset (noise) due to the optoelectronic receiver. Then, background-subtracted signals from polarization channels (parallel and orthogonal) were range-corrected, calibrated, and summed to obtain the total backscatter signal (4). This total signal is used to generate range-time intensity (RTI) plots of the agricultural aerosol emissions. The rangecorrected background-subtracted signals from each channel were also used to calculate the volume depolarization ratio $\delta_{\mathrm{v}}$ by applying (3). The next step is to compute the particle depolarization ratio $\delta_{\mathrm{p}}$ (depolarization ratio of the agricultural aerosols) by applying (8).

Finally, a basic error propagation study has been carried out so as to assess the impact of absolute errors $\left|\Delta K^{*}\right|$ and $\left|\Delta R_{\mathrm{p}}\right|$ which are considered the two dominating error sources in this study, on the estimated particle depolarization ratio (8). An extensive error treatment of the depolarization lidar problem has been presented in [36] and is out of the scope of the present work. At this point, it is worth mentioning that in (8), both $\delta_{\mathrm{v}}$ and $\delta_{\mathrm{b}}$ are functions of $K^{*}$ via (3), which is the constitutive equation defining the volume depolarization ratio. Therefore, the absolute error on the volume depolarization can be written as

$$
\left|\Delta \delta_{i}\right|=\left|\frac{\Delta K^{*}}{\left(K^{*}\right)^{2}}\right|\left|\left(\frac{U_{\perp}}{U_{\|}}\right)_{i}\right|
$$

where subscript $i=\mathrm{b}, \mathrm{v}$ stands for "background" or "volume" measurement, respectively.

When (12) is combined with the basic error propagation of (8),

$$
\left|\Delta \delta_{\mathrm{p}}\right|=\left|\frac{\Delta \delta_{\mathrm{p}}}{\Delta \delta_{\mathrm{b}}}\right|\left|\Delta \delta_{\mathrm{b}}\right|+\left|\frac{\Delta \delta_{\mathrm{p}}}{\Delta \delta_{\mathrm{v}}}\right|\left|\Delta \delta_{\mathrm{v}}\right|+\left|\frac{\Delta \delta_{\mathrm{p}}}{\Delta R_{\mathrm{p}}}\right|\left|\Delta R_{\mathrm{p}}\right|,
$$


the sought-after absolute error $\left|\Delta \delta_{\mathrm{p}}\right|$ in response to absolute errors $\Delta K^{*}$ and $\Delta R_{\mathrm{p}}$ is obtained.

\section{Results and Discussion}

3.1. Volume Depolarization Ratio Measurements. Figure 2 presents the RTI plots of the aerosol clouds corresponding to trials T2, T5, T9, and T10. The left-hand column shows the range-corrected total backscatter power, and the righthand column shows the volume depolarization ratio per trial. Figure 2(a) presents the dust cloud emitted during trial T2; the cloud approached the lidar position as the sprayer advanced along alley 2. Trial T5, shown in Figure 2(b), included dynamic spraying along alley 5; a mixture of spray drift and field dust was generated. In comparison with trial $\mathrm{T} 2$, the cloud had a greater dispersion (up to $70 \mathrm{~m}$ laterally) due to the greater distance between the sprayer and the laser beam.

Trial T9, shown in Figure 2(c), was conducted in field no. 2 with the sprayer in a static position. Volume depolarization ratio had lesser values in trial T9 than in trials T2 and T5, because in trial T9 only spray drift was generated, while in trials T2 and T5 field dust was also emitted. Figure 2(d) shows trial T10, which was similar to trial T9 except in the nozzles used (Table 1) and the sprayer position (Figure 1). Interestingly, two clouds, each corresponding to a different type of aerosol, were identified. The first cloud was detected from the beginning of the trial to approximately $80 \mathrm{~s}$ and was due to dust ejected into the air by a passing car on a dirt road next to the field. A second cloud was detected from 85 onwards and was due to spray drift. The comparison of both clouds shows that the range-corrected total backscatter power by spray drift is an order of magnitude greater. In contrast, the greatest volume depolarization ratio is caused by the road dust.

3.2. Particle Depolarization Ratio Measurements. For each trial, Table 2 presents the types of aerosols emitted as well as the mean value and standard deviation of the volume background depolarization ratio $\delta_{\mathrm{b}}$ and the particle depolarization ratio $\delta_{\mathrm{p}}$ of the aerosol as it has been defined by (8).

From the measurements of the particle depolarization ratio, four types of aerosols have been identified: spray drift, diesel exhaust, field dust, and road dust. Spray drift $\delta_{\mathrm{p}}$ ranges between 0.028 and 0.043 . The Lorenz-Mie theory states that spherical particles do not modify the original polarization state of the light at the backscattering direction [37]. The sphericity of the droplets was laboratory tested by means of a phase Doppler analyzer (57X10 PDA, Dantec Dynamics, Skovlunde, Denmark); $3 \%$ to $20 \%$ of the generated droplets at the nozzle output were not spherical, which explains the resulting depolarizations.

Depolarization of tractor engine exhaust emissions has been determined $\left(\delta_{p}=0.099\right)$ in trial T1. To the best of our knowledge, only relative depolarization ratios of diesel exhaust have been measured in a previous study [38]. It should be noted that relative depolarizations of diesel exhaust obtained in the cited study are below the background depolarization, which does not happen in our case. As these authors point out, the composition and the depolarization ratio of exhaust emissions is greatly influenced by the combustion efficiency.

Field dust is raised by the tractor as it moves along the alleys. $\delta_{\mathrm{p}}$ of 0.220 and 0.268 have been measured in trials T2 and T3, respectively. These results are in good agreement with atmospheric lidar measurements of Saharan dust $\left(\delta_{\mathrm{p}}=0.24-0.28\right.$ at $355 \mathrm{~nm}$ [36]). The high depolarization associated with the dust is explained by the irregular shape of crystalline particles that constitute it.

Trials T4 and T5 are examples of spray drift tests where the cloud is contaminated by dust. In fact, resulting depolarization ratios $\left(\delta_{\mathrm{p}} \approx 0.21\right)$ demonstrate that dust predominates over spraying in the monitored clouds. Polarization lidar technique opens the possibility of computing the fraction of each type of aerosol in mixture clouds as presented here. For instance, $\delta_{\mathrm{p}}$ is currently used to separate dust from nondust in atmospheric research [39]. Its application in farming requires a laboratory characterization of $\delta_{\mathrm{p}}$ of main agricultural aerosols.

Road dust raised by the car (trial T10) presents $\delta_{\mathrm{p}}=0.385$, a value similar to that obtained in previous road dust measurements $\left(\delta_{\mathrm{p}}=0.33-0.37\right.$ at $355 \mathrm{~nm}$ [40]) carried out under controlled conditions. The higher $\delta_{\mathrm{p}}$ of the road dust in comparison to field dust is attributed to a different composition of the road floor, with an important presence of gravel.

Figure 3 represents, by means of normalized histograms, the distribution functions of the particle depolarization ratio for all the types of aerosols analysed in this study. This graph evidences the ability to distinguish and identify each of the agricultural aerosols through $\delta_{\mathrm{p}}$.

As discussed in Section 2.3, the two main sources of error in $\delta_{\mathrm{p}}$ are the cross-calibration constant $K^{*}$ and the backscatter ratio $R_{\mathrm{p}}$. $K^{*}$ can be affected by the existence of a small amount of aerosols in the calibration layer [36]. From (5), if $\delta_{\mathrm{v}}$ was 0.005 , that is, $20 \%$ higher than the molecular depolarization ratio $\delta_{\mathrm{m}}$, then $K^{*}$ would vary by $-9 \%$.

To compute $R_{\mathrm{p}}$, ideal clouds (with no extinction) have been assumed in (10) and (11). For dust measurements, the uncertainty of $R_{\mathrm{p}}$ can be estimated by assuming an extinction coefficient of $0.15 \mathrm{~km}^{-1}$ at $355 \mathrm{~nm}$ [41] and a cloud depth equal to $25 \mathrm{~m}$ (typical value for the clouds of this study). This yields a variation of $-1 \%$ on $R_{\mathrm{p}}$.

The numerical calculation of (12) and (13) for previous uncertainties on $K^{*}$ and $R_{\mathrm{p}}$ gives relative errors of about $10-12 \%$ and $17-19 \%$ on particle depolarization ratios of spray drift and dust, respectively. These are acceptable error figures, similar to those obtained in other lidar polarization experiments [33].

\section{Conclusions}

The results show that the detection of agricultural aerosol emissions with the polarization lidar technique is feasible 

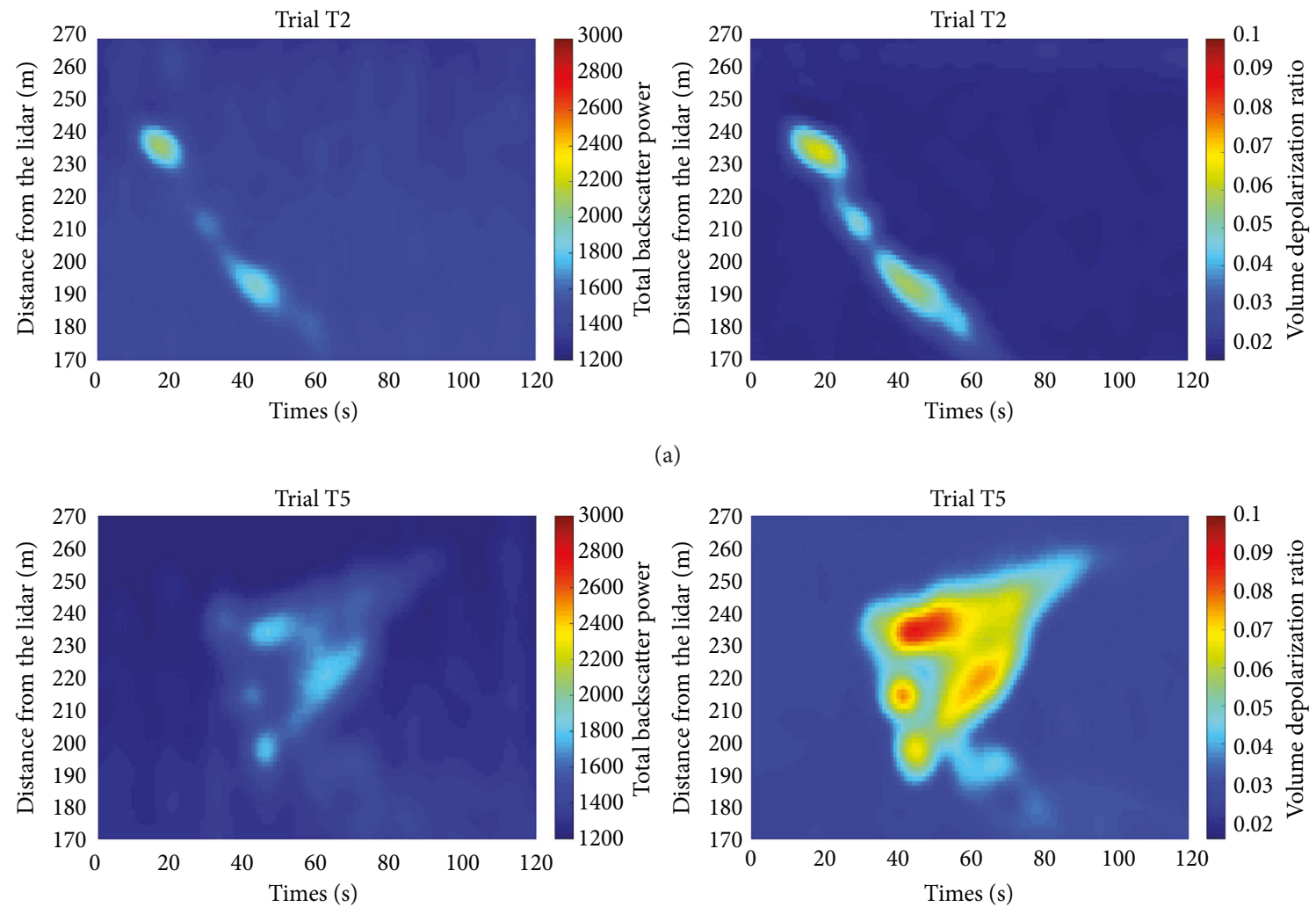

(a)

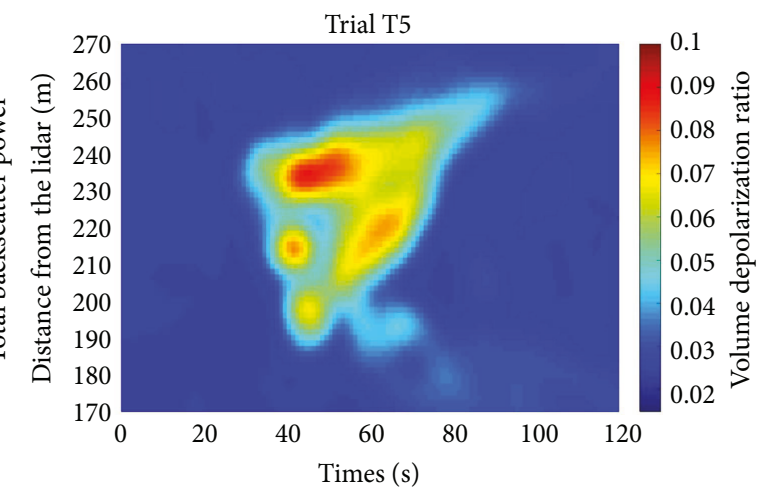

(b)
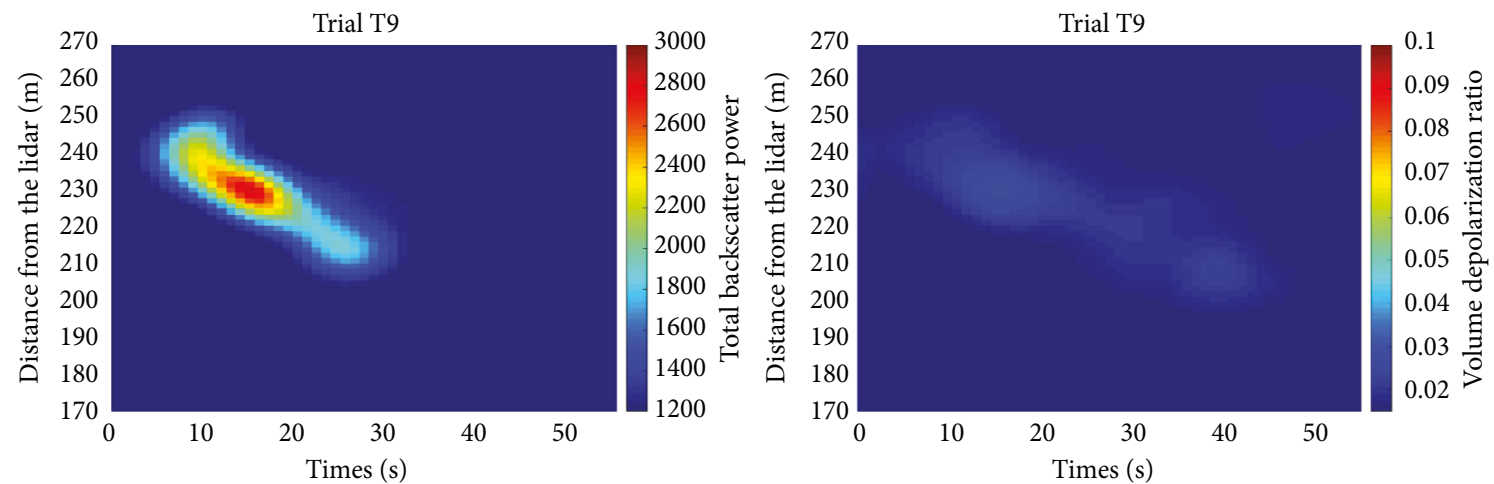

(c)
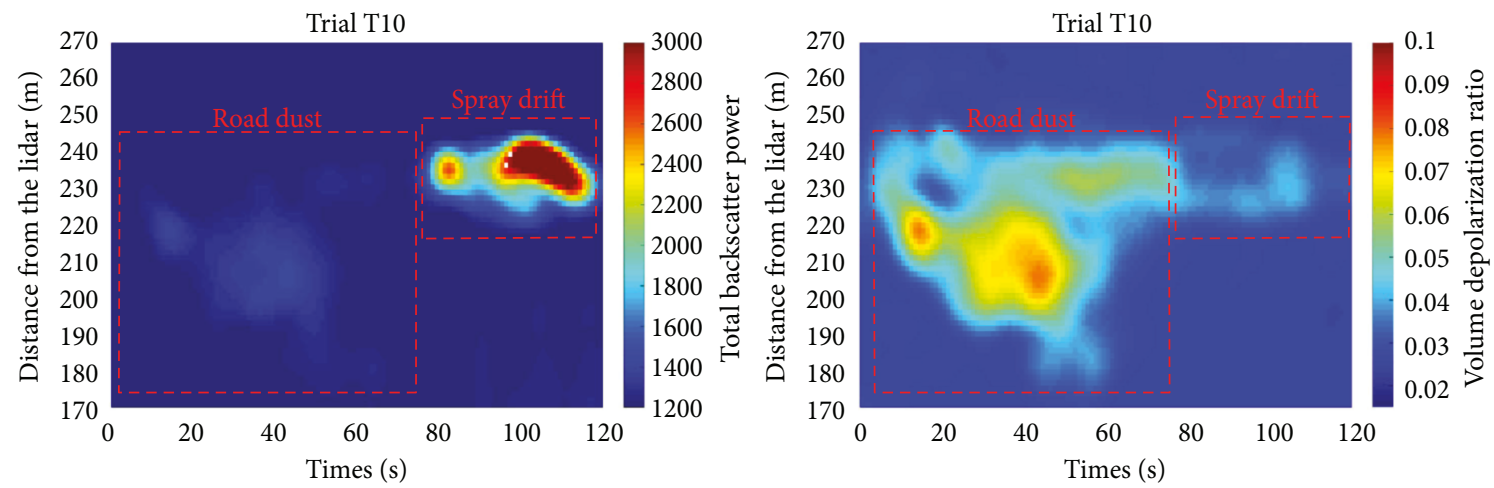

(d)

Figure 2: (Left) Range-corrected total backscatter power (arbitrary units). (Right) Volume depolarization ratio. (a) Trial T2: dynamic trial without spraying (alley 2, field no. 1). (b) Trial T5: dynamic spraying at $540 \mathrm{rpm}$ (alley 5, field no. 1). (c) Trial T9: static spraying (field no. 2). (d) Trial T10: static spraying (field no. 2). 
TABLE 2: Type of aerosol detected in each trial, volume background depolarization ratio $\left(\delta_{\mathrm{b}}\right)$, and particle depolarization ratio of the aerosol $\left(\delta_{\mathrm{p}}\right)$. For each depolarization value, the mean and the standard deviation are given.

\begin{tabular}{lccc}
\hline Trial & Type of aerosol & $\delta_{\mathrm{b}}$ & $\delta_{\mathrm{p}}$ \\
\hline T1 & Diesel exhaust & $0.018 \pm 0.0007$ & $0.099 \pm 0.0075$ \\
T2 & Field dust & $0.019 \pm 0.0004$ & $0.220 \pm 0.0376$ \\
T3 & Field dust & $0.020 \pm 0.0011$ & $0.268 \pm 0.0402$ \\
T4 & Mixture of spray drift and field dust & $0.026 \pm 0.0006$ & $0.218 \pm 0.0512$ \\
T5 & Mixture of spray drift and field dust & $0.027 \pm 0.0007$ & $0.213 \pm 0.0660$ \\
T6 & Spray drift & $0.013 \pm 0.0003$ & $0.035 \pm 0.0080$ \\
T7 & Spray drift & $0.014 \pm 0.0003$ & $0.028 \pm 0.0054$ \\
T8 & Spray drift & $0.015 \pm 0.0009$ & $0.043 \pm 0.0086$ \\
T9 & Spray drift & $0.016 \pm 0.0016$ & $0.033 \pm 0.0092$ \\
T10 & Road dust/spray drift & $0.025 \pm 0.0008$ & $0.385 \pm 0.0568 / 0.034 \pm 0.0082$ \\
\hline
\end{tabular}

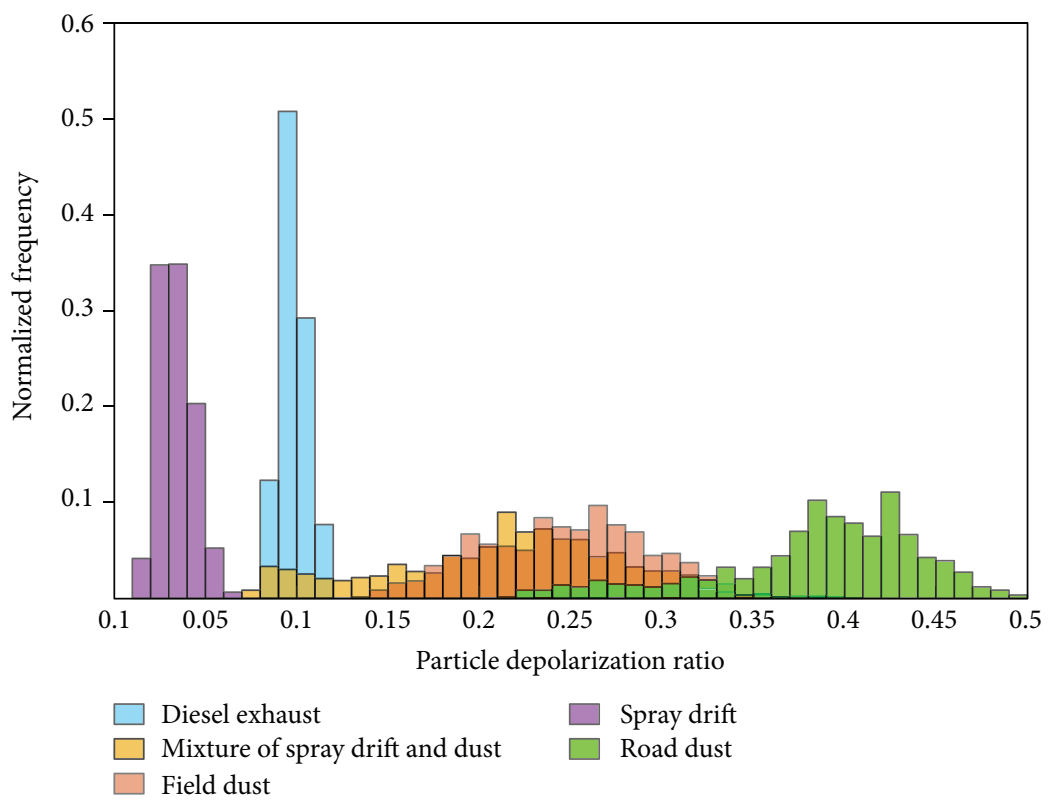

Figure 3: Distribution of particle depolarization ratio for spray drift (T6-T10), diesel exhaust (T1), mixture of spray drift and dust (T4 and $\mathrm{T} 5)$, field dust (T2 and T3), and road dust (T10).

and allows the simultaneous measurement and discrimination of aerosols of different origin. Measurements of spray drift, diesel exhaust, field dust, and road dust emissions had corresponding $\delta_{\mathrm{p}}$ values divergent enough to adequately identify them. This technique is also able to monitor the spatiotemporal evolution of PM clouds, which is a powerful method for understanding this phenomenon. The obtained results encourage further research to improve this technique by developing polarization lidar systems specifically designed for agricultural applications. Future work should also include a laboratory characterization of particle depolarization ratios due to agricultural aerosols. A robust knowledge of $\delta_{\mathrm{p}}$ will allow to determine the fraction of each aerosol in mixed clouds usually caused by agricultural activities.

\section{Conflicts of Interest}

The authors declare no conflicts of interest.

\section{Acknowledgments}

This research was partially funded by the Spanish Ministry of Economy and Competitiveness (projects AGL200766093-C04-03, AGL2010-22304-04-C03-03, and AGL201348297-C2-2-R) and EU FEDER. Secretaria d'Universitats i Recerca del Departament d'Economia i Coneixement de la Generalitat de Catalunya and the Spanish Ministry of Education are thanked for Mr. Jordi Gené's predoctoral fellowships (2016FI_B 00669 and FPU15/03355). The authors would like to thank the Institut de Recerca $\mathrm{i}$ 
Tecnologia Agroalimentàries for allowing the use of their experimental fields. The authors also wish to thank F. Camp, A. Escolà, C. Garcerá, F. Gràcia, J. Masip, E. Moltó, I. del Moral, and R. Viana for their assistance in the field work. X. Torrent and S. Planas are also thanked for the nozzle characterization with the PDA. F. Marenco (Met Office, UK) and P. Chazette (LSCE-IPLS, France) are acknowledged for their fruitful comments about lidar calibration.

\section{References}

[1] J. W. Erisman, A. Bleeker, A. Hensen, and A. Vermeulen, "Agricultural air quality in Europe and the future perspectives," Atmospheric Environment, vol. 42, no. 14, pp. 32093217, 2008.

[2] V. P. Aneja, W. H. Schlesinger, and J. W. Erisman, "Effects of agriculture upon the air quality and climate: research, policy, and regulations," Environmental Science \& Technology, vol. 43, no. 12, pp. 4234-4240, 2009.

[3] F. Van den Berg, R. Kubiak, W. G. Benjey et al., "Emission of pesticides into the air," Water, Air, \& Soil Pollution, vol. 115, no. 1/4, pp. 195-218, 1999.

[4] S. R. Yates, L. L. McConnell, C. J. Haperman, S. K. Papiernik, S. Gao, and S. L. Trabue, "Managing agricultural emissions to the atmosphere: state of the science, fate and mitigation, and identifying research gaps," Journal of Environmental Quality, vol. 40, no. 5, pp. 1347-1358, 2011.

[5] J. B. Unsworth, R. D. Wauchope, A. W. Klein et al., "Significance of the long range transport of pesticides in the atmosphere," Pure and Applied Chemistry, vol. 71, no. 7, pp. 1359-1383, 1999.

[6] B. A. Holmén, W. E. Eichinger, and R. G. Flocchini, "Application of elastic lidar to PM10 emissions from agricultural nonpoint sources," Environmental Science \& Technology, vol. 32, no. 20, pp. 3068-3076, 1998.

[7] B. A. Holmén, T. A. James, L. L. Ashbaugh, and R. G. Flocchini, "Lidar-assisted measurement of PM10 emissions from agricultural tilling in California's San Joaquin Valley part I: lidar," Atmospheric Environment, vol. 35, no. 19, pp. 3251-3264, 2001.

[8] B. A. Holmén, T. A. James, L. L. Ashbaugh, and R. G. Flocchini, "Lidar-assisted measurement of PM10 emissions from agricultural tilling in California's San Joaquin Valley part II: emission factors," Atmospheric Environment, vol. 35, no. 19, pp. 3265-3277, 2001.

[9] A. L. Hiscox, D. R. Miller, B. A. Holmén, W. Yang, and J. Wang, "Near-field dust exposure from cotton field tilling and harvesting," Journal of Environmental Quality Abstract Special Submissions, vol. 37, no. 2, pp. 551-556, 2008.

[10] G. E. Bingham, C. C. Marchant, V. V. Zavyalov et al., "Lidar based emissions measurement at the whole facility scale: method and error analysis," Journal of Applied Remote Sensing, vol. 3, no. 1, article 033510, 2009.

[11] W. B. Willis, W. E. Eichinger, J. H. Prueger et al., "Lidar method to estimate emission rates from extended sources," Journal of Atmospheric and Oceanic Technology, vol. 34, no. 2, pp. 335-345, 2017.

[12] A. Behrendt, S. Pal, V. Wulfmeyer, A. M. B. Valdebenito, and G. Lammel, "A novel approach for the characterization of transport and optical properties of aerosol particles near sources. Part I: measurement of particle backscatter coefficient maps with a scanning UV lidar," Atmospheric Environment, vol. 45, no. 16, pp. 2795-2802, 2011.

[13] R. M. Hoff, R. E. Mickle, and F. A. Froude, "A rapid acquisition lidar system for aerial spray diagnostics," Transactions of the ASAE, vol. 32, no. 5, pp. 1523-1528, 1989.

[14] R. E. Mickle, "Utilizing vortex behaviour to minimize drift," Journal of Environmental Science and Health, Part B, vol. 29, no. 4, pp. 621-645, 1994.

[15] R. E. Mickle, "Influence of aircraft vortices on spray cloud behaviour," Journal of the American Mosquito Control Association-Mosquito News, vol. 12, no. 2, pp. 372-379, 1996.

[16] D. R. Miller and T. E. Stoughton, "Response of spray drift from aerial applications at forest edge to atmospheric stability," Agricultural and Forest Meteorology, vol. 100, no. 1, pp. 4958, 2000.

[17] D. R. Miller, L. R. Khot, A. L. Hiscox, M. Salyani, T. W. Walker, and M. Farooq, "Effect of atmospheric conditions on coverage of fogger applications in a desert surface boundary layer," Transactions of the ASABE, vol. 55, no. 2, pp. 351361, 2012.

[18] A. L. Hiscox, D. R. Miller, C. J. Nappo, and J. Ross, “Dispersion of fine spray from aerial applications in stable atmospheric conditions," Transactions of the ASABE, vol. 49, no. 5, pp. 1513-1520, 2006.

[19] L. R. Khot, D. R. Miller, A. L. Hiscox, M. Salyani, T. W. Walker, and M. Farooq, "Extrapolation of droplet catch measurements in aerosol application treatments," Atomization and Sprays, vol. 21, no. 2, pp. 149-158, 2011.

[20] E. Gregorio, J. R. Rosell-Polo, R. Sanz et al., "LIDAR as an alternative to passive collectors to measure pesticide spray drift," Atmospheric Environment, vol. 82, pp. 83-93, 2014.

[21] E. Gregorio, X. Torrent, S. Planas de Martí et al., "Measurement of spray drift with a specifically designed lidar system," Sensors, vol. 16, no. 12, p. 499, 2016.

[22] T. E. Stoughton, D. R. Miller, Y. Yang, and K. M. Ducharme, "A comparison of spray drift predictions to lidar data," Agricultural and Forest Meteorology, vol. 88, no. 1-4, pp. 15-26, 1997.

[23] J. Wang, A. L. Hiscox, D. R. Miller, and T. W. Sammis, "A dynamic Lagrangian, field-scale model of dust dispersion from agriculture tilling operations," Transactions of the ASABE, vol. 51, no. 5, pp. 1763-1774, 2008.

[24] J. Wang, A. L. Hiscox, D. R. Miller, and T. W. Sammis, "A comparison of Lagrangian model estimates to light detection and ranging (LIDAR) measurements of dust plumes from field tilling," Journal of the Air \& Waste Management Association, vol. 59, no. 11, pp. 1370-1378, 2009.

[25] C. C. Marchant, T. D. Wilkerson, G. E. Bingham et al., "Aglite lidar: a portable elastic lidar system for investigating aerosol and wind motions at or around agricultural production facilities," Journal of Applied Remote Sensing, vol. 3, no. 1, article 033511, 2009.

[26] E. Gregorio, F. Rocadenbosch, R. Sanz, and J. R. Rosell-Polo, "Eye-safe lidar system for pesticide spray drift measurement," Sensors, vol. 15, no. 2, pp. 3650-3670, 2015.

[27] R. M. Schotland, K. Sassen, and R. J. Stone, "Observations by lidar of linear depolarization ratios by hydrometeors," Journal of Applied Meteorology, vol. 10, no. 5, pp. 1011-1017, 1971.

[28] K. Sassen, "Polarization in lidar," in Lidar. Range-Resolved Optical Remote Sensing of the Atmosphere, C. Weitkamp, Ed., Springer, New York, NY, USA, 2005. 
[29] T. Murayama, N. Sugimoto, I. Uno et al., "Groundbased network observation of Asian dust events of April 1998 in East Asia," Journal of Geophysical Research, vol. 106, no. D16, pp. 18345-18359, 2001.

[30] M. C. Pitts, L. R. Poole, and L. W. Thomason, "CALIPSO polar stratospheric cloud observations: second-generation detection algorithm and composition discrimination," Atmospheric Chemistry and Physics, vol. 9, no. 19, pp. 7577-7589, 2009.

[31] M. I. Mishchenko and K. Sassen, "Depolarization of lidar returns by small ice crystals: an application to contrails," Geophysical Research Letters, vol. 25, no. 3, pp. 309-312, 1998.

[32] S. Lolli, L. Sauvage, S. Loaec, and M. Lardier, "EZ Lidar: a new compact autonomous eye-safe scanning aerosol Lidar for extinction measurements and PBL height detection. Validation of the performances against other instruments and intercomparison campaigns," Optica Pura y Aplicada, Sociedad Española de Óptica, vol. 44, no. 1, pp. 33-41, 2011.

[33] F. Marenco and R. Hogan, "Determining the contribution of volcanic ash and boundary layer aerosol in backscatter lidar returns: a three-component atmosphere approach," Journal of Geophysical Research, vol. 116, no. 116, article D00U06, 2011.

[34] P. Chazette, A. Dabas, J. Sanak, M. Lardier, and P. Royer, "French airborne lidar measurements for Eyjafjallajökull ash plume survey," Atmospheric Chemistry and Physics, vol. 12, no. 15, pp. 7059-7072, 2012.

[35] R. T. H. Collis and P. B. Russell, "Lidar measurement of particles and gases by elastic backscattering and differential absorption," in Laser Monitoring of the Atmosphere, E. D. Hinkley, Ed., pp. 71-151, Springer, Berlin/Heidelberg, Germany, 1976.

[36] V. Freudenthaler, M. Esselborn, M. Wiegner et al., "Depolarization-ratio profiling at several wavelengths in pure Saharan dust during SAMUM 2006," Tellus B: Chemical and Physical Meteorology, vol. 61, no. 1, pp. 165-179, 2009.

[37] L. R. Bissonnette, "Lidar and multiple scattering," in Lidar. Range-resolved optical remote sensing of the atmosphere, C. Weitkamp, Ed., pp. 43-103, Springer, New York, NY, USA, 2005.

[38] S. D. Mayor, S. M. Spuler, B. M. Morley, and E. Loew, "Polarization lidar at $1.54 \mu \mathrm{m}$ and observations of plumes from aerosol generators," Optical Engineering, vol. 46, no. 9, article 096201, 2007.

[39] R. E. Mamouri and A. Ansmann, "Fine and coarse dust separation with polarization lidar," Atmospheric Measurement Techniques, vol. 7, no. 11, pp. 3717-3735, 2014.

[40] X. Cao, G. Roy, and R. Bernier, "Lidar polarization discrimination of bioaerosols," Optical Engineering, vol. 49, no. 11, article 116201, 2010.

[41] A. Papayannis, D. Balis, V. Amiridis et al., "Measurement of Saharan dust aerosols over the Eastern Mediterranean using elastic backscatter-Raman lidar, spectrophotometric and satellite observations in the frame of the EARLINET project," Atmospheric Chemistry and Physics, vol. 5, no. 8, pp. 20652079, 2005. 


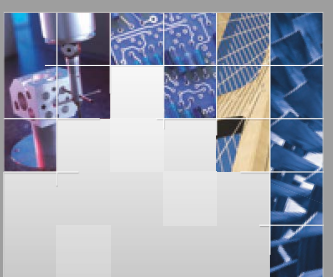

\section{Enfincering}
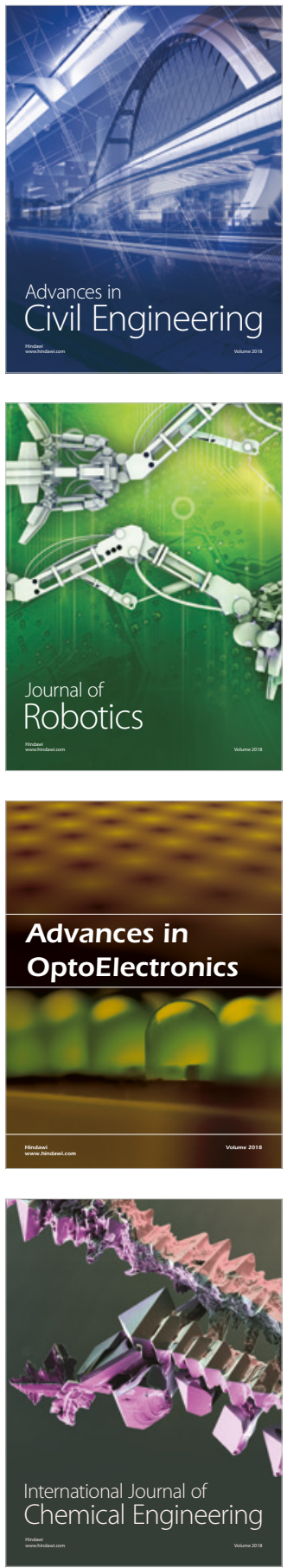

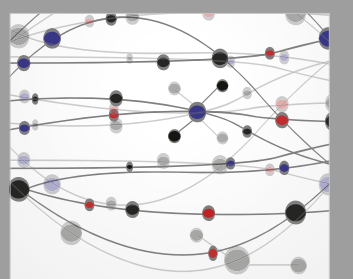

\section{Rotating \\ Machinery}

The Scientific World Journal

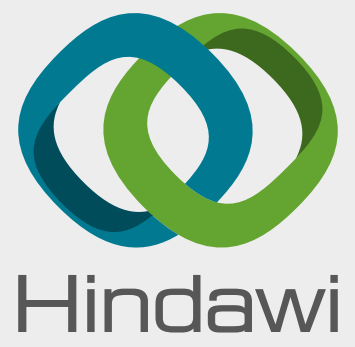

Submit your manuscripts at

www.hindawi.com
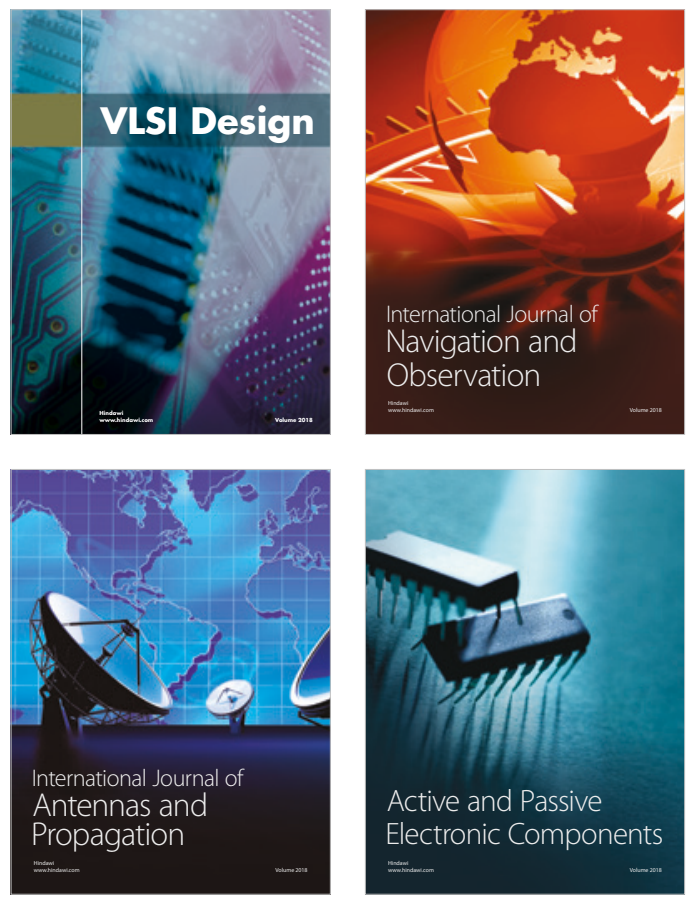
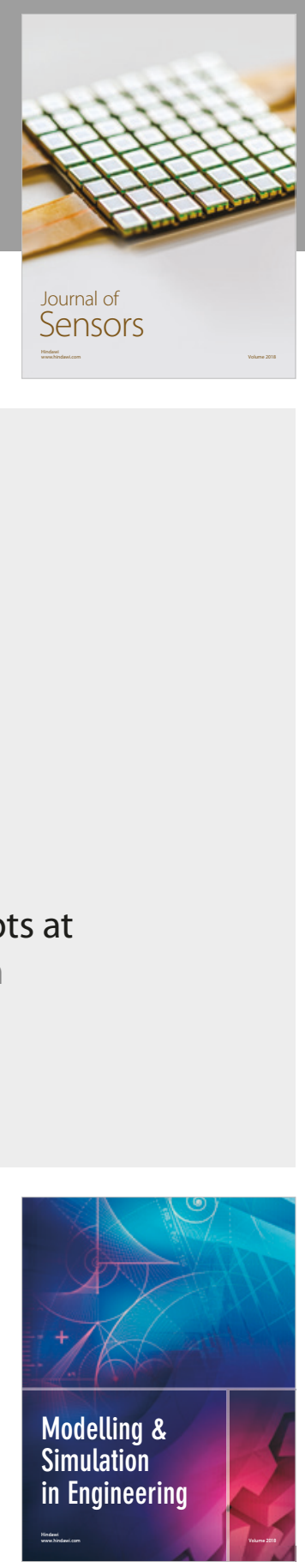

\section{Advances \\ Multimedia}
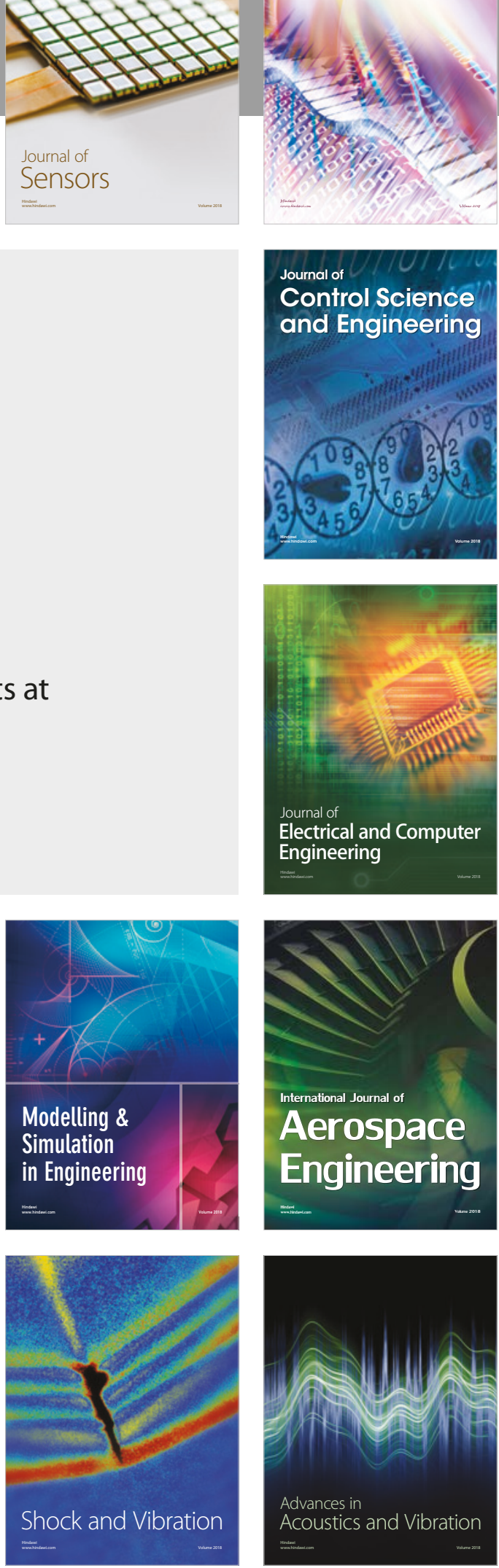